\title{
QUEEN'S
UNIVERSITY
BELFAST
}

\section{On the role of magnesium in a LiF:Mg,Ti thermoluminescent dosimeter}

Massillon-JI, G., Johnston, C. S. N., \& Kohanoff, J. (2018). On the role of magnesium in a LiF:Mg,Ti

thermoluminescent dosimeter. Journal of Physics: Condensed Matter, 31(2), 025502.

https://doi.org/10.1088/1361-648X/aaee62

Published in:

Journal of Physics: Condensed Matter

Document Version:

Peer reviewed version

Queen's University Belfast - Research Portal:

Link to publication record in Queen's University Belfast Research Portal

Publisher rights

Copyright 2019 IOP. This work is made available online in accordance with the publisher's policies. Please refer to any applicable terms of use of the publisher.

\section{General rights}

Copyright for the publications made accessible via the Queen's University Belfast Research Portal is retained by the author(s) and / or other copyright owners and it is a condition of accessing these publications that users recognise and abide by the legal requirements associated with these rights.

Take down policy

The Research Portal is Queen's institutional repository that provides access to Queen's research output. Every effort has been made to ensure that content in the Research Portal does not infringe any person's rights, or applicable UK laws. If you discover content in the Research Portal that you believe breaches copyright or violates any law, please contact openaccess@qub.ac.uk. 


\title{
On the role of magnesium in $\mathrm{LiF}: \mathrm{Mg}$, Ti thermoluminescent dosimeters
}

\author{
Guerda Massillon-JL ${ }^{1, a, b)}$, Conrad S.N. Johnston ${ }^{2}$, and Jorge Kohanoff ${ }^{2}$ \\ ${ }^{1}$ Instituto de Física, Universidad Nacional Autónoma de México, 04510 Coyoacan Mexico City, México \\ ${ }^{2}$ Atomistic Simulation Centre, Queen's University Belfast, Belfast BT7 1NN, Northern Ireland, United Kingdom
}

\begin{abstract}
LiF}$ doped with $\mathrm{Mg}$ and $\mathrm{Ti}$ is the most widely used thermoluminescent (TL) dosimeter for a large variety of applications. It has been argued that the Mg dopant is the most important defect in the TL process. Besides the common F-centre defects in LiF, optical absorption measurements have suggested the presence of Mg-related absorption bands at $380 \mathrm{~nm}(3.26 \mathrm{eV})$, and $310 \mathrm{~nm}(4.0 \mathrm{eV})$ when LiF:Mg is exposed to ionizing radiation, whose origin is not yet well understood. This work presents an investigation of the role of defects induced by $\mathrm{Mg}$ interstitials in LiF through electronic structure calculations. The calculations show that $\mathrm{Mg}$ interstitials induce a local lattice distortion characterized by the displacement of two opposite fluorine atoms, adjacent to the magnesium, away from their original sites by an average distance of $0.6 \AA$ each, while the closest Li atoms are displaced by $0.1 \AA$. This defect introduces electronic states in the band-gap that can trap excess electrons produced during irradiation, thus enhancing the efficiency of the detector. Holes, on the other hand, are created and trapped in orbitals of mainly Mg- $3 s$ character. Additionally, the results suggest that irradiation can simultaneously remove a Li atom nearby a Mg interstitial; substitute a Li by a Mg atom or create a Li vacancy plus a Mg substitutional, giving rise to defects within the $\mathrm{LiF}$ gap that are more stable thermodynamically than the $\mathrm{Mg}$ interstitial itself. Interestingly, under irradiation the energy levels obtained for LiF:Mg-Lisub $\mathrm{e}^{-}(3.486 \mathrm{eV})$ and $\mathrm{LiF}: \mathrm{Mg}+\mathrm{e}^{-}(4.224$ eV) defects are very close to the experimental absorption bands.
\end{abstract}

PACS numbers: 31.15.E-, 31.15.es, 61.72.-y

\section{Introduction}

Lithium fluoride doped with magnesium and titanium (LiF:Mg,Ti) is the most commonly used thermoluminescent (TL) material. Its applications include occupational personal dosimetry, environmental monitoring, and medical and space dosimetry [1-4]. However, despite its success, the basic processes which give rise to this crystal's TL response to ionising radiation fields are not yet well understood [1-4]. Over the past 70 years, considerable work has been

\footnotetext{
a) To whom correspondence should be addressed. Electronic mail: massillon@fisica.unam.mx

b) GMJL was in sabbatical visit at Queen's University Belfast while performing this research
} 
devoted to the identification of the defects responsible for this TL-response [5-16]. The difficulty of this challenge is demonstrated by the complex structure of the TL glow-curve, produced by measuring intensity of light emitted as the material is heated following irradiation. Fig. 1 shows an example of such a glow-curve, which can exhibit over 10 peaks [5-6]. Such peaks have been ascribed to specific defect states in the material, on the basis of phenomenological models that consider the flow of electrons and holes between trapped states [16]. Experimental studies have indicated that specific peaks can be assigned to traps created by $\mathrm{Mg}$ and Ti dopants [5-6].

Doped with $\mathrm{Mg}$ alone, $\mathrm{LiF}$ will produce TL peaks from room temperature to more than $300^{\circ} \mathrm{C}$, where the absolute maximum is located around $220^{\circ} \mathrm{C}$ (see Fig. 1). The luminescence yields of LiF:Mg are relatively small [7]. The intensity, however, can be enhanced by a factor of 10 by co-doping with $\mathrm{Ti}$, without distorting the curve [7]. From this, it can be inferred that $\mathrm{Mg}$ is responsible for creating the necessary traps, and that $\mathrm{Ti}$ serves to stabilize the traps. When $\mathrm{LiF}$ has been doped with other species, such as $\mathrm{Cu}$ and $\mathrm{P}$, it has been shown that the $\mathrm{Mg}$ concentration remains the key parameter for achieving TL efficiency [8]. This study also showed that the $\mathrm{Mg}$ concentration affects the dose-response and linear energy transfer (LET: rate of energy deposited per unit length of a charged projectile [4]) dependence of the detector $[8]$.

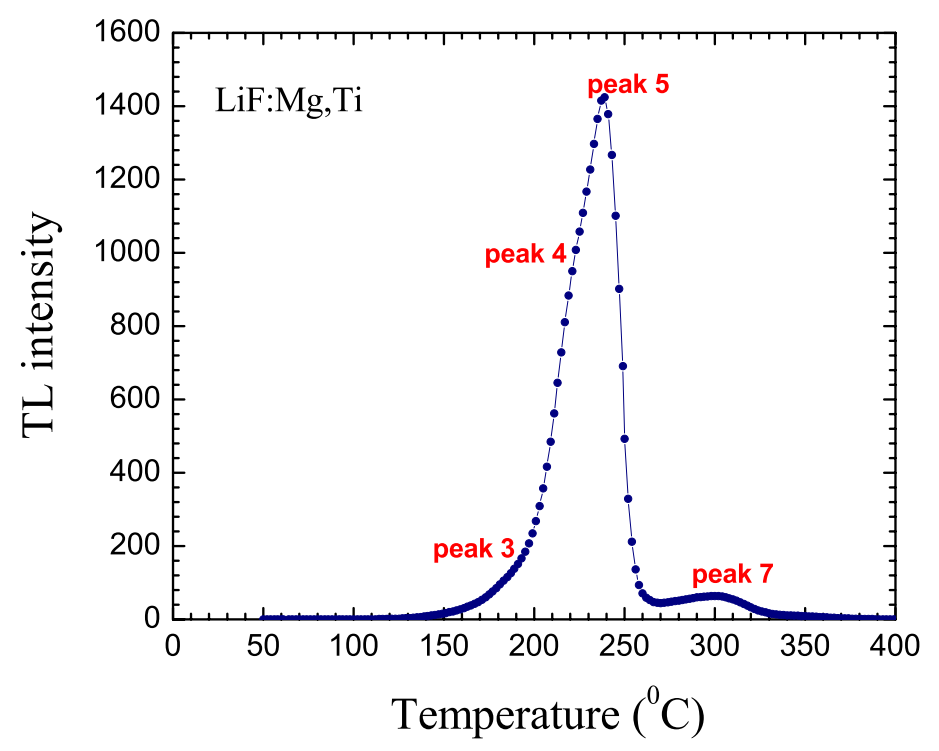

FIG.1 LiF:Mg,Ti TL glow-curve induced by 5 Gy of $100 \mathrm{keV}$ average-energy x-rays displaying various peaks ascribed to different defect-states. 
Having established that the role of magnesium dopants is to create trap states, we now consider what form these traps take. One possibility proposed to explain the peak at around $220^{\circ} \mathrm{C}$ is that it is due to clusters of $\mathrm{Mg}-\mathrm{Li}_{\mathrm{vac}}$ ( $\mathrm{Li}$ vacancies) [6]. Early work suggested that holes would be trapped near complexes of $\mathrm{Mg}^{2+}$ ions and vacancies, while the TL centre would be a nearby colour centre (F-centre) defect [9]. Recent ab initio calculations [17] have confirmed that the F vacancy in $\mathrm{LiF}$ indeed gives rise to an F-centre that manifests itself in optical absorption spectra. Optical absorption studies of LiF:Mg exposed to ionizing-radiation have suggested the presence of Mg-related absorption bands at $380 \mathrm{~nm}(3.26 \mathrm{eV})$, and $310 \mathrm{~nm}(4.0 \mathrm{eV})$ in addition to the Fcentres [9-15]. Several phenomenological defect models have been presented to explain the origin of these bands, particularly the one at $310 \mathrm{~nm}$, but its true origin is still controversial. Mort [10], Crittenden et al. [11], and Seth et al. [12] concluded that the $4 \mathrm{eV}$ band is associated to a $\mathrm{Z}_{2}$-centre (a divalent magnesium ion adjacent to an $\mathrm{F}^{\prime}$-centre, that is an F-centre which has trapped an additional electron). On the contrary, a study performed by Klick et al. [9] found no evidence of a $\mathrm{Z}_{2}$-centre in $\mathrm{LiF}: \mathrm{Mg}$, but this was attributed to the possibility that trapped hole bands obscure the $\mathrm{Z}_{2}$-centre signal. Independently, Nepomnyashchikh and Radzhabov have been more categorical by affirming that there is no $\mathrm{Z}_{2}$-centre formed in the $\mathrm{LiF}: \mathrm{Mg}$ crystal, but instead there is a $3 s \rightarrow 3 p$ electronic transition in the $\mathrm{Mg}^{+}$ions [15]. According to Mayhugh et $a l$. , the $4 \mathrm{eV}$ band is due to a trapped electron centre [13-14].

From the theoretical point of view, Shluger et al. [18] have investigated the electronic structure of $\mathrm{O}^{2-}-\mathrm{V}_{\mathrm{a}}, \mathrm{Mg}_{\mathrm{c}}-\mathrm{O}_{\mathrm{a}}$, and $\mathrm{Mg}_{\mathrm{c}}{ }^{+}-\mathrm{V}_{\mathrm{a}} \mathrm{V}_{\mathrm{c}}$ centres in the $\mathrm{LiF}$ crystal using the semi-empirical intermediate neglect of differential overlap (INDO) method, a simplified version of HartreeFock theory. They concluded that only the $\mathrm{Mg}^{+}-\mathrm{V}_{\mathrm{c}} \mathrm{V}_{\mathrm{a}}$ centres could be radiation-induced and the photobleaching of these centres at $4 \mathrm{eV}$ is associated with a new absorption band at $3.5 \mathrm{eV}$, which could be due to the $\mathrm{V}_{\mathrm{k}}$ centres having absorption in LiF in the same region [18]. Furthermore, they concluded that "the common feature of the impurity centers in LiF is the existence of quasi-local states within the valence band, the optical transition from which result on the formation of the self-trapped holes ( $V_{k}$ centres) irrespective of whether dealing with cation or anion sublattice defect" [18]. Density functional theory (DFT) calculations have been reported for the structure and stability of defects in a wide variety of materials [19-21]. A recent calculation [17] has focused on the F vacancy in LiF. However, to the best of our knowledge, there is no other published study about the role of the Mg defect in LiF that is based on DFT using hybrid functionals. 
In this work we present first-principles electronic structure calculations of defect states induced by $\mathrm{Mg}$-interstitials in $\mathrm{LiF}$, and we analyse their role. We show that, electronically, such defects produce lattice distortion by the displacement of fluorine atoms, in the sense of introducing acceptor electronic states in the band-gap that can trap excess electrons during irradiation. We also analyse the geometric distortions associated with the introduction of defects.

\section{Computational Details}

Electronic structure calculations were carried out using the freely available, open-source code, CP2K [22-24] which implements density functional theory (DFT) using the Gaussian and plane waves (GPW) method [25]. A thorough test of basis sets in combination with several plane wave density cutoffs has been performed through the cell optimization of the pristine LiF using a $4 \times 4 \times 4$ supercell (512 atoms). A difference of $0.04 \%$ (16.105 $\AA$ versus $16.112 \AA)$ on the supercell's lattice constant at the PBE0 level was observed compared to the experiment for the DZVP-MOLOPT-SR-GTH basis set with a plane wave cutoff of 1000 Ry (see Table I of supplemental material). Similarly, for a 3x3x3 supercell (216 atoms), the resulting supercell's lattice constant was $12.076 \AA$, also in extremely good agreement with experiment, differing by only $0.07 \%$. Core electrons were replaced by norm-conserving Goedecker-Teter-Hutter pseudopotentials [26-27], used in conjunction with the DZVP-MOLOPT-SR-GTH basis set [28] together with a plane wave cutoff of 1000 Ry for the finest of four grids in the multigrid solution of the Poisson equation for the density, which was adequate for the purposes of the present investigation. A convergence threshold of $10^{-6}$ Ha was used for the total energy selfconsistency.

The PBE [29] exchange-correlation functional was used as a reference. PBE, as an example of a generalized-gradient approximation (GGA) functional, suffers from some well-documented limitations, such as underestimating the band-gap and misplacing defect levels. These are mostly due to the introduction of an important self-interaction error. As will be shown, in the present case of LiF, PBE is unsuitable for defect calculations. To overcome these limitations, we have assessed the performance of three different hybrid functionals that have been proved effective in correcting band-gaps and defect energy levels [30]. Firstly, we considered PBE0 [31-32], which features 25\% Hartree-Fock (HF) exchange and the PBE semi-local functional, and the Minnesota M06-2X [33-34] functional that combines 54\% HF exchange with a metaGGA. Both are global hybrids, as opposed to range-separated versions that are generally more 
suitable for extended systems. Besides, we also considered the range-separated screened hybrid functional, HSE06 [35-37]. We found this choice not to be particularly important in the present case because the defect-states are all well-localized already at the PBE level. Therefore, after carefully scrutinising the performance of these three functionals in comparison with available experimental data, a better agreement was observed with PBE0 data, so we decided to use PBE0 (see Table II of supplemental material). All calculations reported in the results section have thus been obtained with this functional. To reduce the cost of the Hartree-Fock calculation needed for the hybrid functionals, we used the auxiliary density matrix method [38-39]. Hybrids like PBE0 only correct for the non-locality of the exchange interaction. There is, however, a nonlocal contribution to correlation due to dynamical polarization, which results in the well-known van der Waals interaction. While bonding in LiF is mostly of ionic character, we nevertheless included van der Waals correlation corrections through Grimme's DFT-D3 pair potential [40]. Notice that the primary effect of this potential is on lattice parameters and internal geometry, which in this case includes structural distortions introduced by defects. Changes in electronic properties due to the Grimme correction are of second order. All calculations were spinpolarised using the unrestricted Kohn-Sham formalism.

\section{Defect Calculations}

Based on the result of the optimization test, a lattice constant of $4.028 \AA$ was adopted for the cubic LiF unit cell [41]. The unit cell was replicated into a $3 \times 3 \times 3$ supercell containing 216 atoms, and the cell volume and atomic positions were allowed to relax using the PBE0 functional. The relaxation convergence criteria were the following: a) $3 \times 10^{-3} \mathrm{Bohr}$ as the maximum displacement of an atom from the previous step; b) $1.5 \times 10^{-3} \mathrm{Bohr}$ as the root mean square (RMS) displacement of all atoms from the previous step; c) $4.5 \times 10^{-4} \mathrm{Ha} / \mathrm{Bohr}$ as the maximum force on any atom; and d) $3 \times 10^{-4} \mathrm{Ha} / \mathrm{Bohr}$ as the RMS forces on all atoms. By increasing the supercell size from $3 \times 3 \times 3$ (216 atoms) to $4 \times 4 \times 4$ (512 atoms) defect formation energies changed by less than $1 \%$. Based on these results, we decided to use the supercell containing 216 atoms and to sample the Brillouin zone only at the Gamma-point. Five defect states were prepared, as summarized in Fig 2. Note that the illustrative structures shown in Figure 2 are the initial conditions before relaxation. To study the F vacancy defect, a lattice F atom was removed from the $\mathrm{LiF}$ bulk. We call this defect $\mathrm{LiF}-\mathrm{F}_{\text {vac }}$ (Figure $2 \mathrm{~b}$ ). For the $\mathrm{Mg}$ dopant, four scenarios were studied: 1) insertion of a $\mathrm{Mg}$ atom into a tetrahedral interstitial position of LiF bulk [42-43], named LiF:Mg (Figure 2c); 2) substitution of a Li atom by a Mg 
atom, called $\mathrm{LiF}: \mathrm{Mg}-\mathrm{Li}_{\text {sub }}$ (Figure 2d); 3) insertion of a $\mathrm{Mg}$ atom into an interstitial position together with the creation of a $\mathrm{Li}$ vacancy $\left(\mathrm{Li}_{\mathrm{vac}}\right)$ by removing a nearby lattice $\mathrm{Li}$ atom from the LiF bulk, named LiF:Mg-Livac (Figure 2e); 4) substitution of a Li atom by a Mg together with the creation of a nearby $\mathrm{Li}_{\mathrm{vac}}$, called $\mathrm{LiF}: \mathrm{Mg}-\mathrm{Li}_{\text {sub }}-\mathrm{Li}_{\mathrm{vac}}$ (Figure $2 \mathrm{f}$ ). For each of these defective structures, the atomic positions were relaxed using the same relaxation convergence criteria indicated above. The final structures obtained after optimization will be discussed later. In addition, we considered these same systems with the addition of an unpaired electron that occupies the lowest-lying defect-state located within the large LiF gap of $14.2 \mathrm{eV}$ [44]. In these cases, the negative charge was compensated with a positive uniform background. Any other induced defect-states in the gap observed at higher energies are empty. For comparison, we carried out calculations for pure $\mathrm{LiF}$.

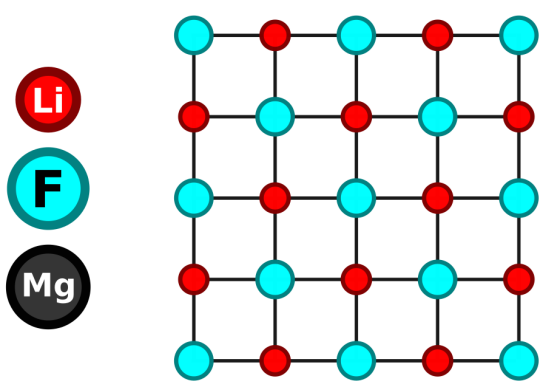

(a) LiF

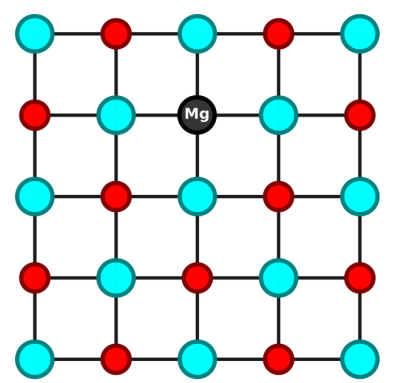

(d) LiFMg-Li $\mathrm{Lub}_{\text {sub }}$

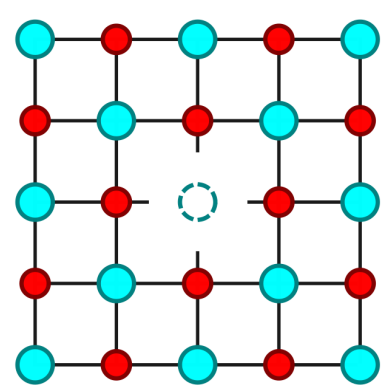

(b) LiF- $\mathrm{F}_{\text {vac }}$

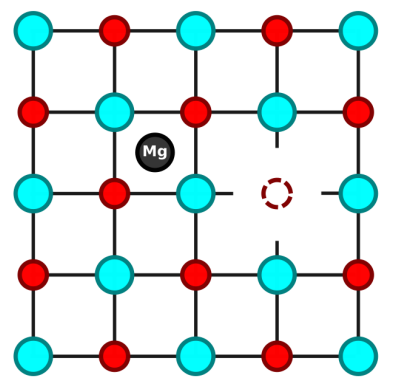

(e) LiFMg-Li

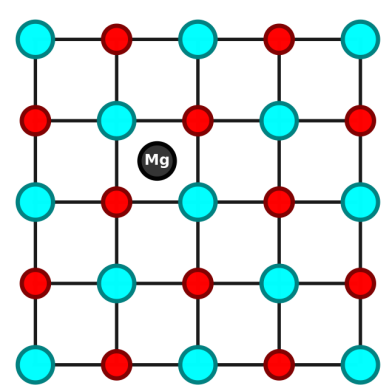

(c) LiFMg

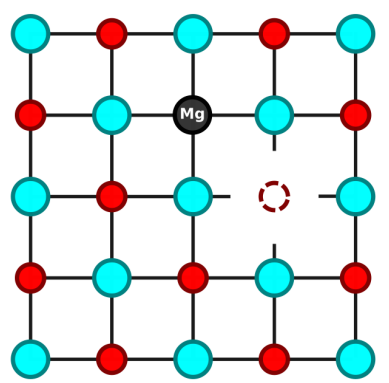

(f) $\mathrm{LiFMg}-\mathrm{Li}_{\text {sub }}-\mathrm{Li}_{\text {vac }}$

FIG. 2 Simplified illustrative structures for the initial configurations. Lithium, fluorine, and magnesium atoms are depicted as red, cyan, and black filled circles, respectively. Vacancies are indicated with an empty circle. The structures shown are (a) pristine LiF, (b) LiF with a fluorine vacancy, (c) LiF with a magnesium interstitial, (d) $\mathrm{LiF}$ with a substitutional $\mathrm{Mg}$, (e) LiF with a Li vacancy plus a $\mathrm{Mg}$ interstitial and (f) LiF with a Li vacancy plus a substitutional Mg. The actual supercells used in the calculations contain between 215 and 217 atoms.

In addition, calculations for the $\mathrm{F}_{2}$ molecule, and $\mathrm{Mg}$ and $\mathrm{Li}$ bulks have been performed to evaluate the formation energy of the defects. Lattice constants for the cubic Li and hexagonal 
$\mathrm{Mg}$ unit cell were taken from the literature [45]. Similar to the LiF with defects, the unit cells were replicated into a $5 \times 5 \times 5$ supercell containing 250 atoms and sampled at the Gammapoint to be consistent with the LiF calculations. The cell volume was allowed to relax using the PBE0 functional. The formation energies of the various charged defects were calculated as proposed in [46]:

$$
E_{f}\left(X^{q}\right)=E_{\text {tot }}\left(X^{q}\right)-E_{\text {tot }}(\text { bulk })-\sum_{i} n_{i} \mu_{i}+q E_{F}
$$

where $E_{\text {tot }}\left(X^{q}\right)$ and $E_{\text {tot }}$ (bulk) are the total energies of the system containing the defect, $X$, and of the perfect crystal, respectively, using the same supercell; $\pm n_{i}$ are the number of atoms that have been added (+) or removed (-) from the supercell to form the defect of type $i$, and $\mu_{i}$ are the chemical potentials calculated in this work as the total energy per atom of the $F_{2}$ molecule, and $\mathrm{Mg}$ and Li bulk, using the same functional and basis sets as in the supercell calculations. $E_{F}$ is the Fermi energy, and varies from zero, i.e. the valence band maximum (VBM), up to the conduction band minimum (CBM), i.e. the bandgap calculated for the system. For comparison between LiF bulk and the defected structures, the VBM of the supercell containing the defect was aligned with that of the bulk. In this work, the formation energy for the neutral systems has been computed for the same charge state $q=0$, while for the charged systems, a constant charge state $q=-1$ was considered and the formation energy was calculated at the same Fermi energy. Consequently, the comparison between two charged systems is expected to be independent of the Fermi energy.

The thermodynamic transition level (TTL), $\varepsilon^{\text {therm }}\left(q_{1} / q_{2}\right)$, of a defect is defined as the value of the Fermi energy, $E_{F}$, for which two charge states $q_{1}=0$ and $q_{2}=-1$ have the same formation energy, $E_{f}$, i.e. [46]:

$$
E_{f}\left(X^{0} ; E_{F}=\varepsilon^{\text {therm }}(0 /-1)\right)=E_{f}\left(X^{-1} ; E_{F}=\varepsilon^{\text {therm }}(0 /-1)\right)
$$

Using Eq. (1) and Eq. (2), the TTL can be obtained as described below:

$$
\varepsilon^{\text {therm }}(0 /-1)=E_{\text {tot }}\left(X^{-1}\right)-E_{\text {tot }}\left(X^{0}\right)
$$


The problem with this approach is that the total energy $\left(E_{t o t}\right)$ calculated for charged periodic systems includes a contribution from the compensating background and is therefore not directly comparable with that of the neutral system. An alternative is to appeal to Janak's theorem [47], to write:

$$
E_{\text {tot }}\left(X^{-1}\right)-E_{t o t}\left(X^{0}\right)=\int_{0}^{1} \varepsilon_{i+1}(N+n) d n
$$

where $\varepsilon_{i+1}(N)$ corresponds to the eigenvalue of the lowest unoccupied state $(i+1)$ of the $N$ electron system with a neutral defect. A good approximation to the integral in Eq. (4) is to evaluate it via the trapezium rule using only the extreme points, instead of calculating $\mathcal{E}_{i+1}(N+n)$ for many values of $n$ between 0 and 1 [48]. That is:

$$
\varepsilon^{\text {therm }}(0 /-1)=E_{\text {tot }}\left(X^{-1}\right)-E_{\text {tot }}\left(X^{0}\right)=\left[\mathcal{E}_{i+1}(N)+\mathcal{E}_{i+1}(N+1)\right] / 2
$$

where $\varepsilon_{i+1}(N+1)$ is the eigenvalue of the highest occupied state of the $(N+1)$-electron system, i.e. the charged defect system. These eigenvalues are all referred to the VBM and are accessible to our neutral and charged defect calculations. In addition, it is possible to estimate optical transition levels by considering the relaxation energy, $E_{r e l}$, that corresponds to the energy difference between relaxed and initial charged defect structures [48], i.e.

$$
\varepsilon^{o p t}(0 /-1)=\varepsilon^{\text {therm }}(0 /-1)+E_{r e l}
$$

According to Freysoldt et al. [46], the experimental meaning of the TTL is that for any Fermilevel position situated below $\varepsilon^{\text {therm }}\left(q_{1} / q_{2}\right)$, the defect is stable in charge $q_{1}$, but if the Fermi energy is found above $\varepsilon^{\text {therm }}\left(q_{1} / q_{2}\right)$, then the charge state $q_{2}$ is stable. Optical transition levels, $\varepsilon^{o p t}\left(q_{1} / q_{2}\right)$, can be observed in photoluminescence experiments [48], where the charged defect system is not allowed to relax.

\section{Results}

\subsection{Defect energy levels}

In the left panel of Figure 3 we show the total projected density of states (PDOS) for some of 
the systems studied, namely: (a) pristine $\mathrm{LiF}$, (c) F vacancy, (e) LiF:Mg, and (g) LiF:Mg-Livac. The systems with substitutional Mg exhibit PDOS similar to those with interstitial $\mathrm{Mg}$. The energy levels are reported in Table I, below. The right panel shows the PDOS for the same systems with the addition of an electron. The zero was aligned to the valence band maximum (VBM), and the curves have been smoothed using Gaussians of $0.2 \mathrm{eV}$ width. A side effect of this procedure is a slight broadening of the peaks. We have not portrayed the separate spin components for the sake of clarity.

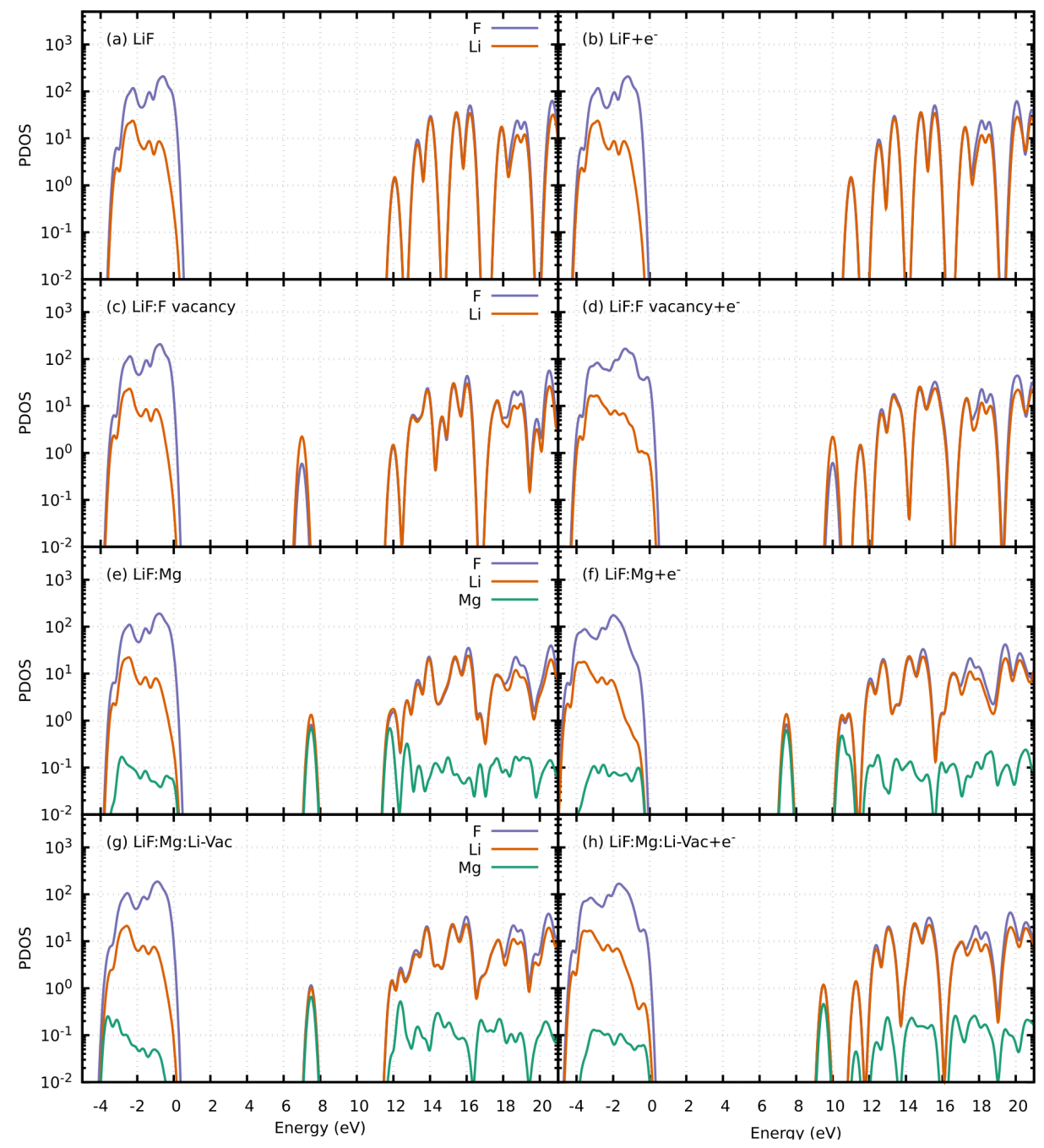

FIG.3. Projected spin-up density of states as a function of energy for all the configurations studied, calculated at the PBE0 level. Configurations are labelled in the panels. Colours and line types indicate the contributions of the various atom types to the PDOS: F (blue), $\mathrm{Li}$ (orange), and Mg (green). The zero was aligned to the top of the valence band.

PBE results reported in Table I indicate a pristine LiF gap of $9.06 \mathrm{eV}$, a single defect-state for 
LiF:Mg, which is essentially the Mg-3s state hybridized with orbitals of the neighbouring $\mathrm{F}$ and $\mathrm{Li}$ atoms, and two defect-states for the $\mathrm{LiF}: \mathrm{Mg}-\mathrm{Li}_{\text {vac }}$ as well as $\mathrm{LiF}: \mathrm{Mg}-\mathrm{Li}_{\text {sub }}$ while for $\mathrm{LiF}: \mathrm{Mg}-$ $\mathrm{Li}_{\text {sub }}-\mathrm{Li}_{\text {vac }}$, any possible defect state is merged with the conduction band. The $\mathrm{LiF}: \mathrm{Mg}$ state is occupied and located at about $2.27 \mathrm{eV}$, while $\mathrm{LiF}: \mathrm{Mg}-\mathrm{Li}_{\text {vac }}$ features an occupied (Mg dopant) and an unoccupied $\left(\mathrm{Li}_{\mathrm{vac}}\right)$ state situated at around $2.56 \mathrm{eV}$ and $1.46 \mathrm{eV}$ below the conduction band minimum (CBM), respectively. For $\mathrm{LiF}: \mathrm{Mg}_{\mathrm{Li}} \mathrm{i}_{\text {sub }}$, two states located at $1.09 \mathrm{eV}$ (occupied) and $0.73 \mathrm{eV}$ (unoccupied) below the CBM are observed. Upon the addition of an excess electron, the $\mathrm{Mg}$-states shift very slightly upwards by $0.002 \mathrm{eV}$ and $0.043 \mathrm{eV}$ for $\mathrm{LiF}: \mathrm{Mg}$ and $\mathrm{LiF}: \mathrm{Mg}-\mathrm{Li}_{\text {vac}}$, respectively, but no other gap state appears within PBE. However, in the presence of an excess electron, $\mathrm{LiF}: \mathrm{Mg}-\mathrm{Li}_{\text {sub }}$ exhibits one defect state situated at $1.785 \mathrm{eV}$ while $\mathrm{LiF}: \mathrm{Mg}-$ $\mathrm{Li}_{\text {sub- }} \mathrm{Li}_{\text {vac }}$, shows two states localized at $1.095 \mathrm{eV}$ and $0.73 \mathrm{eV}$ below the CBM.

TABLE I. Kohn-Sham energy levels of the defects, $\mathrm{E}_{\mathrm{CBM}}-\mathrm{E}_{\mathrm{DS}}$, in $\mathrm{eV}$.

\begin{tabular}{lccc}
\hline Defect-state & PBE & PBEO & Experiment \\
\hline LiF-gap & 9.06 & 12.075 & $14.2 \pm 2^{44}$ \\
\hline F vacancy 1 & 3.420 & 5.064 & $5.061^{11}$ \\
\hline F vacancy 2 & 1.629 & 1.866 & --- \\
\hline LiF:Mg & 2.270 & 4.534 & $4.428^{10-15}$ \\
\hline$\left(\mathrm{LiF}: \mathrm{Mg}+\mathrm{e}^{-}\right)^{1}$ & 2.268 & 4.865 & --- \\
\hline$\left(\mathrm{LiF}: \mathrm{Mg}+\mathrm{e}^{-}\right)^{2}$ & --- & 4.224 & $4.000^{10-15}$ \\
\hline$\left(\mathrm{LiF}: \mathrm{Mg}+\mathrm{e}^{-}\right)^{3}$ & ---- & 2.688 & \\
\hline$\left(\mathrm{LiF}: \mathrm{Mg}-\mathrm{Li}_{\text {vac }}\right)^{1}$ & 2.557 & 4.487 & \\
\hline$\left(\mathrm{LiF}: \mathrm{Mg}-\mathrm{Li}_{\text {vac }}\right)^{2}$ & 1.461 & 1.584 & \\
\hline $\mathrm{LiF}: \mathrm{Mg}-\mathrm{Li}_{\text {vac }}+\mathrm{e}^{-}$ & 2.514 & 4.544 & \\
\hline (LiF:Mg-Li $\left._{\text {sub }}\right)^{1}$ & 1.092 & 2.889 & \\
\hline (LiF:Mg-Li $\left._{\text {sub }}\right)^{2}$ & 0.728 & 0.919 & \\
\hline $\mathrm{LiF}: \mathrm{Mg}-\mathrm{Li}_{\text {sub }}+\mathrm{e}^{-}$ & 1.785 & 3.486 & $3.263^{10-15}$ \\
\hline $\mathrm{LiF}: \mathrm{Mg}-\mathrm{Li}_{\text {sub- }}-\mathrm{Li}_{\text {vac }}$ & ---- & ---- & \\
\hline (LiF:Mg-Li $\left._{\text {sub }}-\mathrm{Li}_{\text {vac }}+\mathrm{e}^{-}\right)^{1}$ & 1.095 & 2.898 & \\
\hline (LiF:Mg-Li $\left._{\text {sub }}-\mathrm{Li}_{\text {vac }}+\mathrm{e}^{-}\right)^{2}$ & 0.730 & 0.922 & \\
\hline
\end{tabular}

All hybrid functionals confirm the assignment of the above $\mathrm{Mg}$ defect-state, although at a deeper level. This is shown in Fig. 3(e) and 3(g) and numerical values are given in Table I for 
PBE0. Similar results are observed for the Mg substitutional defects. While there are some discrepancies between the various hybrid functionals, they provide a similar general picture. Therefore, to avoid distracting attention from the main point of the present paper, we are only reporting the PBE0 results. Interestingly, all these defect-states are located at similar energies (PBE0 values around 4.5-5 eV), and very close to experimental data. For better comparison with the experimental data, Table I reports the energy difference between the conduction-band minimum $\left(\mathrm{E}_{\mathrm{CBM}}\right)$ and the defect state within the LiF gap $\left(\mathrm{E}_{\mathrm{DS}}\right)$; i.e. $\mathrm{E}_{\mathrm{CBM}}-\mathrm{E}_{\mathrm{DS}}$ as well as the thermodynamic transition level, $\varepsilon^{\text {therm }}(0 /-1)$, evaluated using equation (5). It has been suggested that comparing the Kohn-Sham energy levels directly with experimental results can be misleading [46]. The argument is that the optical transition, $\varepsilon^{o p t}(0 /-1)$, (energy difference between the band gap and the energy of the photon emitted) is the energy level that would be observed in experiments like photoluminescence where, after the transition, the final charge state is not relaxed to its equilibrium configuration [20]. Note that in this case, the experimental band gap should be reproduced accurately by the DFT calculation [48], which is challenging for standard approximations such as LDA and GGA. Other studies have concluded that hybrid functionals that combine Hartree-Fock exchange with DFT exchange-correlation offer a feasible theoretical tool for determining the location of energy levels of deep defects within the band gap of bulk materials [49]. While this information is useful to identify these defect states and understand their nature, the most crucial aspect from the thermodynamic point of view is their stability. To this end, we computed defect formation energies as well as the thermodynamic transition levels, which will be discussed below. Afterwards, we evaluated the optical transition energy for the $\mathrm{LiF}: \mathrm{Mg}+\mathrm{e}^{-}$structure by computing the relaxation energy as the total energy difference between the charged systems before and after relaxation [50] and compared these values with experimental data in Table I.

\subsection{Formation energy and thermodynamic transition levels}

The formation energies evaluated with equation (1) at the same Fermi energy, $E_{F}=0$ for all systems are reported in Table II while Figure 4 presents the results as a function of the Fermi energy relative to the VBM. At the PBE level we obtained an F vacancy formation energy of $9.28 \mathrm{eV}$, to be compared with the value of $8.2 \mathrm{eV}$ reported in [17]. At the PBE0 level we obtained a slightly larger value of $10.33 \mathrm{eV}$. The PBE formation energies for the $\mathrm{Mg}, \mathrm{Mg}-\mathrm{Li}$ vac and $\mathrm{LiF}: \mathrm{Mg}-\mathrm{Li}_{\text {sub }}-\mathrm{Li}_{\text {vac }}$ defects are $8.15 \mathrm{eV}, 7.8 \mathrm{eV}$ and $2.64 \mathrm{eV}$ respectively, i.e. slightly larger than the PBE0 values, except for $\mathrm{LiF}: \mathrm{Mg}-\mathrm{Li}_{\text {sub }}$ with $4.34 \mathrm{eV}$ formation energy at the PBE level, 
which is smaller than the PBE0 value.

Table II. Defect formation energies, $E_{f}$, and thermodynamic transition levels, $\varepsilon^{\text {therm }}(0 /-)$, of various defect-states in $\mathrm{LiF}$ at the PBE0 theory level. Energies in $\mathrm{eV}$.

\begin{tabular}{lcc}
\hline Defect-state & $\boldsymbol{E}_{\boldsymbol{f}}\left(\boldsymbol{E}_{\boldsymbol{F}}=\mathbf{0}\right)$ & $\boldsymbol{\varepsilon}^{\text {therm }}(\mathbf{0} / \mathbf{- 1})$ \\
\hline $\mathrm{LiF}$ & & \\
\hline $\mathrm{LiF}-\mathrm{F}$ vacancy & 10.33 & \\
\hline $\mathrm{LiF}: \mathrm{Mg}$ & 7.463 & \\
\hline $\mathrm{LiF}: \mathrm{Mg}+\mathrm{e}-$ & 15.34 & 8.32 \\
\hline $\mathrm{LiF}: \mathrm{Mg}-\mathrm{Li}_{\text {vac }}$ & 7.29 & \\
\hline $\mathrm{LiF}: \mathrm{Mg}-\mathrm{Li}_{\text {vac }}+\mathrm{e}^{-}$ & 13.92 & 7.49 \\
\hline $\mathrm{LiF}-\mathrm{Mg}-\mathrm{Li}_{\text {sub }}$ & 4.48 & \\
\hline $\mathrm{LiF}-\mathrm{Mg}-\mathrm{Li}_{\text {sub }}+\mathrm{e}^{-}$ & 11.58 & 8.00 \\
\hline LiF-Mg-Li & & \\
\hline LiF-M $-\mathrm{Li}_{\text {vac }}$ & 2.53 & 8.11
\end{tabular}

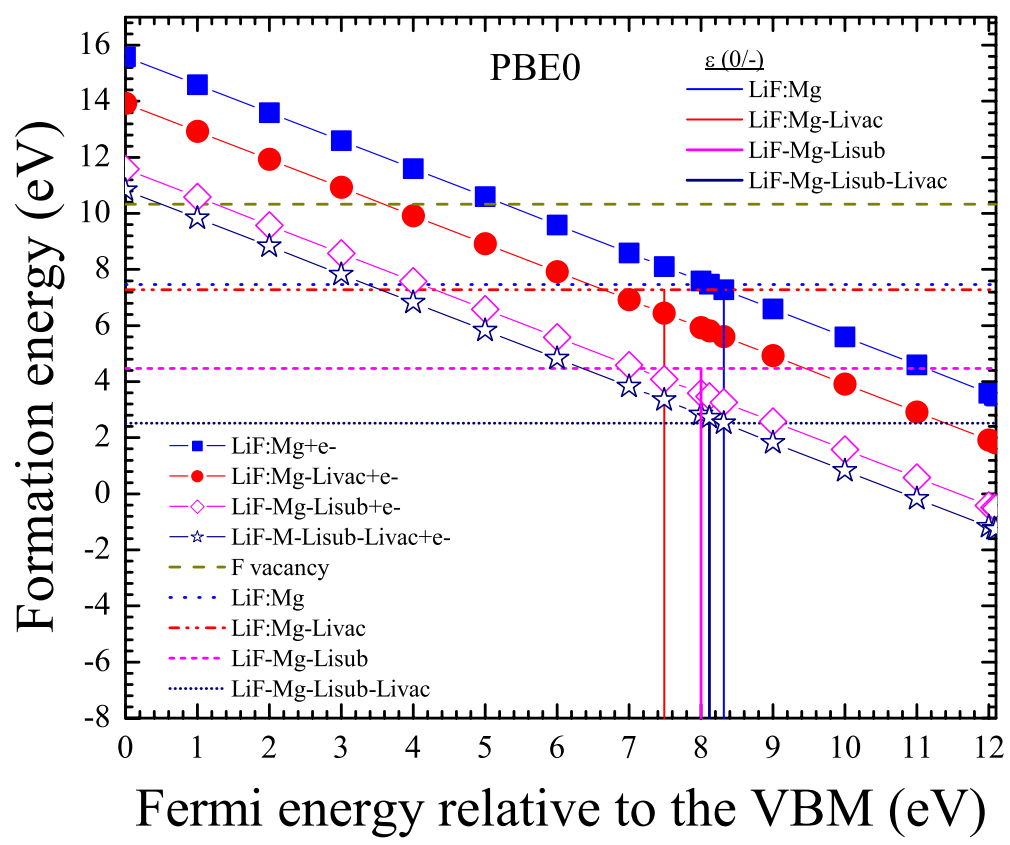

FIG.4. Formation energy as a function of the Fermi energy for the different defects within the LiF gap. The Fermi energy is aligned with the top of the valence band.

As observed in Table II and Figure 4, the results suggest that $\mathrm{LiF}: \mathrm{Mg}-\mathrm{Li}_{\text {sub }}-\mathrm{Li}_{\text {vac }}$ is the most 
stable of all defects, while the F vacancy is the least stable. For the charged system, the LiF:Mg$\mathrm{Li}_{\text {sub }}-\mathrm{Li}_{\text {vac }}+\mathrm{e}^{-}$defect also appears to be more stable than all the defects studied. The thermodynamic transition level (TTL), $\varepsilon^{\text {therm }}(0 /-1)$, calculated for LiF:Mg-Li $\mathrm{vac}_{\mathrm{va}} / \mathrm{LiF}: \mathrm{Mg}-$ $\mathrm{Li}_{\text {vac }}+\mathrm{e}^{-}$system is equal to $7.49 \mathrm{eV}$ and indicated with a solid vertical red line in Figure 4. For the $\mathrm{LiF}: \mathrm{Mg} / \mathrm{LiF}: \mathrm{Mg}+\mathrm{e}^{-}$system, the calculated TTL, $\varepsilon^{\text {therm }}(0 /-1)$, is equal to $8.32 \mathrm{eV}$ and is indicated with a solid vertical blue line in Figure 4. For the LiF-Mg-Li $\mathrm{i}_{\text {sub }} / \mathrm{LiF}-\mathrm{Mg}-\mathrm{Li} \mathrm{i}_{\text {sub }}+\mathrm{e}^{-}$ system, we obtained a TTL equal to $8 \mathrm{eV}$, which is shown by a solid vertical magenta line, while for $\mathrm{LiF}: \mathrm{Mg}-\mathrm{Li}_{\text {sub }}-\mathrm{Li} \mathrm{i}_{\text {vac }} / \mathrm{LiF}: \mathrm{Mg}-\mathrm{Li}_{\text {sub }}-\mathrm{Li}_{\text {vac }}+\mathrm{e}^{-}$the value of the TTL is $8.11 \mathrm{eV}$ and is shown by a solid vertical blue navy line in Figure 4.

\section{Discussion}

\subsection{Defect energy levels}

For the F vacancy - see Fig 3(c) - we observe an occupied state in the gap of $s$ character located in the void created by the removal of the F atom (see Figures $5 \mathrm{a}$ and $5 \mathrm{~b}$ ). In pristine LiF, Fatoms are negatively charged at the expenses of the Li-atoms, due to their electronegativity. The removal of an F-atom frustrates this charge transfer, but the void sustains an electronic state that is still capable of accommodating this transferred charge. The LiF system with an F vacancy has an unpaired electron, and hence a net spin of $1 / 2$. Figure 5 a shows this electronic state as portrayed by the spin density isosurface of value $0.0065 \mathrm{e} / \AA^{3}$, while Figure $5 \mathrm{~b}$ shows a contour plot of two-dimensional projection of the spin density in a plane that contains the $\mathrm{F}$ vacancy. These figures show that this state has unequivocally $s$-angular character and is centred at the F vacancy. Energetically, the defect is located at around $3.5 \mathrm{eV}$ (PBE), $5.064 \mathrm{eV}$ (PBE0) below the CBM. The PBE0 value of $5.064 \mathrm{eV}$ is very close to the reported experimental value of $5.061 \mathrm{eV}$ [11] (see Table I). Such agreement is of similar quality to values previously reported from $a b$ initio many-body calculations, including quantum chemical correlated methods at the CASPT2(ROHF) level (5.22 eV) [17], many-body perturbation calculations including GW and Bethe-Salpeter for excitonic effects: GW $@$ PBE + BSE (5.42 eV) [17], and BSE-corrected DFT approaches like TB-mBJ + BSE (4.9 eV) [17]. These were considered to provide unprecedented agreement with experimental results [17]. 


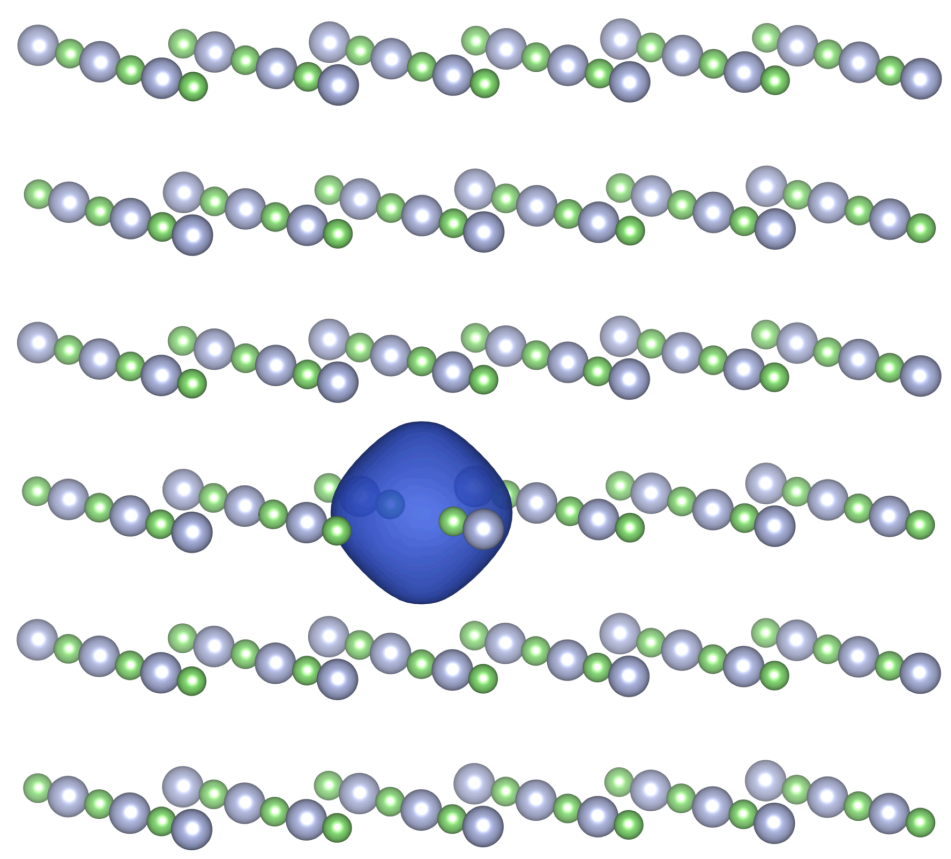

FIG.5a. Spin density isosurface of the LiF:F vacancy. The grey and green symbols represent the F and Li atoms, respectively. The blue surface (value $0.0065 \mathrm{e} / \AA^{3}$ ) is an $s$-like spin density centred at the F vacancy site.

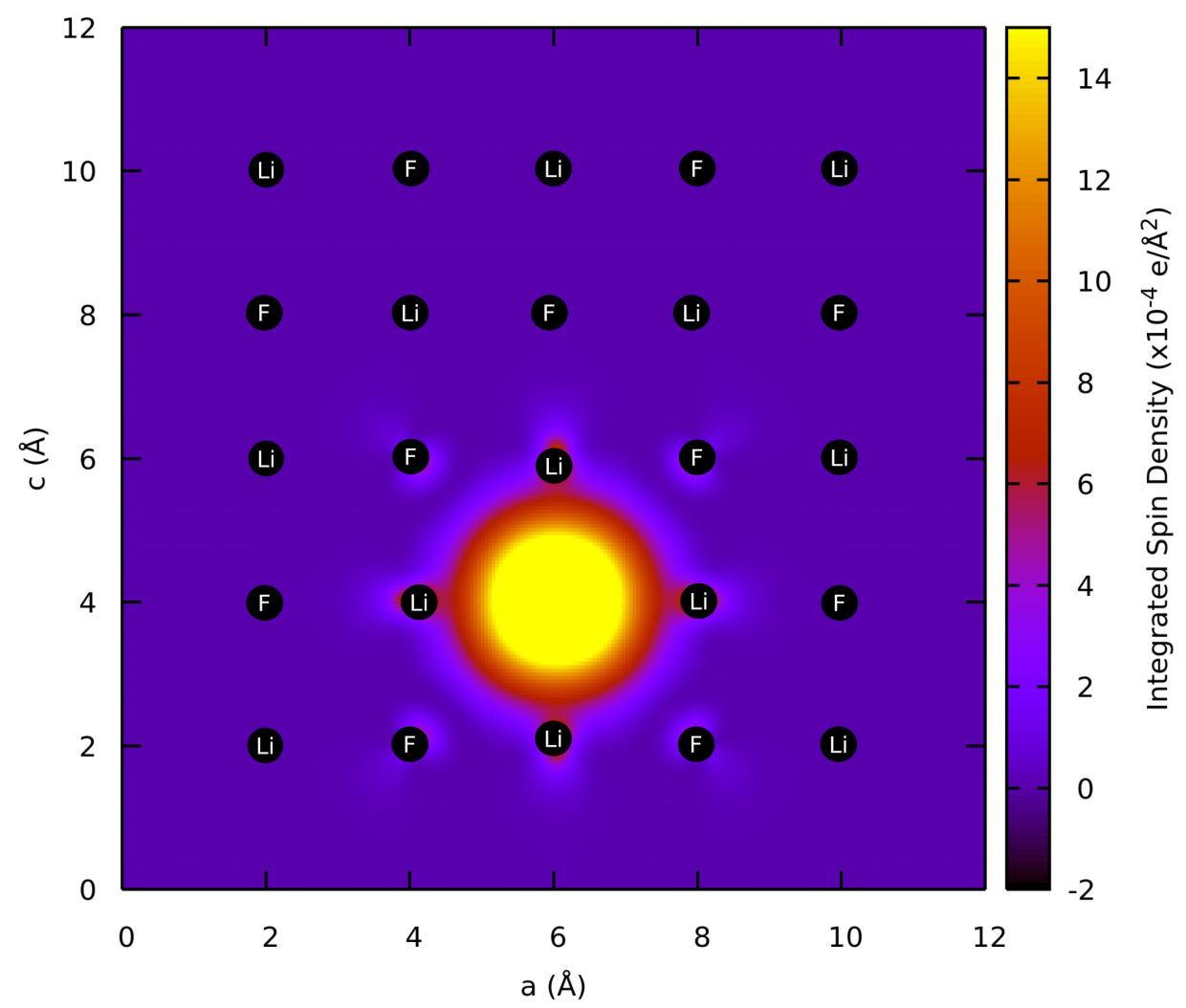

FIG.5b Two-dimensional contour plot of the F vacancy spin density. The central contour is the $s$-like density centred at the $\mathrm{F}$ vacancy, while there is a slightly negative spin density in the neighbouring atoms. Black circles indicate the location of the atoms in the plane of the contour. 
Since $\mathrm{Mg}^{2+}$ is a divalent ion, the LiF:Mg system has no net spin. However, upon electron addition the $\mathrm{LiF}: \mathrm{Mg}+\mathrm{e}^{-}$defect has an unpaired electron that can be characterized by the spin density, similarly to the F vacancy. Contrary to PBE, hybrids exhibit two additional defectstates similar to the reported optical absorption results (Table I). The PDOS (Figure 3(f)) shows two occupied states and an empty state. From the thermoluminescence point of view, these occupied defect-states can be identified as trap-centres where holes in the valence band produced by ionizing radiation may be trapped. The energies of the defects relative to the CBM are reported in Table I as $\left(\mathrm{LiF}: \mathrm{Mg}+\mathrm{e}^{-}\right)^{1},\left(\mathrm{LiF}: \mathrm{Mg}+\mathrm{e}^{-}\right)^{2}$ and $\left(\mathrm{LiF}: \mathrm{Mg}+\mathrm{e}^{-}\right)^{3}$. The first state, $\left(\mathrm{LiF}: \mathrm{Mg}+\mathrm{e}^{-}\right)^{1}$, can be identified with the Mg-3s state in the neutral system, LiF:Mg- The other two states, $\left(\mathrm{LiF}: \mathrm{Mg}+\mathrm{e}^{-}\right)^{2}$ and $\left(\mathrm{LiF}: \mathrm{Mg}+\mathrm{e}^{-}\right)^{3}$, are very interesting. As will be shown below, they are accompanied by a local distortion produced by the presence of the Mg-interstitial.

Furthermore, we notice that, for $\mathrm{LiF}: \mathrm{Mg}^{-} \mathrm{e}^{-}$, apart from the $\mathrm{Mg}$-defect level, there is another occupied state with an energy that, at the PBE0 level, agrees quite well with the experimental value displayed in Table I (4.22 vs $4 \mathrm{eV}$ ), and an empty state at $2.688 \mathrm{eV}$, corresponding to $\left(\mathrm{LiF}: \mathrm{Mg}+\mathrm{e}^{-}\right)^{3}$. Besides, we obtained a relaxation energy, $E_{r e l}=1.7 \mathrm{eV}$ for this system which, by considering the data in Table II, gives an optical transition level, $\varepsilon^{\text {opt }}(0 /-1)=8.32 \mathrm{eV}+1.7$ $\mathrm{eV}=10.2 \mathrm{eV}$. This implies that the energy of the observed photon emitted in the experimental absorption bands, $E_{p h}$, would be the difference between our energy band gap and $\varepsilon^{\text {opt }}(0 /-1)$, i.e. $E_{p h}=12.075 \mathrm{eV}-10.02 \mathrm{eV}=2.055 \mathrm{eV}$, which is smaller than the measured $4 \mathrm{eV}$ absorption band by $\sim 2 \mathrm{eV}$. Nevertheless, given the underestimation of the energy band gap by the PBE0, if we consider the experimental band gap [44] instead, then $E_{p h}=14.2 \mathrm{eV}-10.02 \mathrm{eV}=4.18 \mathrm{eV}$. This value is in excellent agreement with the $4.22 \mathrm{eV}$ value obtained from the Kohn-Sham eigenvalues for the (LiF: $\left.\mathrm{Mg}+\mathrm{e}^{-}\right)^{2}$ defect (see Table I). This result suggests that, at the level of hybrid DFT, the relative difference in energy between the CBM and the KS energy level of the defect is a suitable approximation to the optical absorption band energy, as proposed previously by Alkauskas et al. [49].

In order to understand the origin of these states, we analysed the geometry together with the spin density. In $\mathrm{LiF}: \mathrm{Mg}$, the $\mathrm{Mg}$ sits in a tetrahedral interstitial position in the lattice and induces a small local distortion of the lattice through the displacement of two opposite nearest fluorine and one lithium atoms away from their original positions by distances of $0.6 \AA$ and 0.1 $\AA$, respectively. In the presence of radiation, i.e. when adding an excess electron, we observed 
only small adjustments of distorted structure, with F-atoms moving further away from the $\mathrm{Mg}$ to $0.7 \AA$ and the Li atoms moving back by roughly half the distance they moved in the neutral system $(0.05 \AA)$. The resulting spin densities of the $\mathrm{LiF}: \mathrm{Mg}+\mathrm{e}^{-}$system are presented in Figures $6 \mathrm{a}$ (isosurface) and 6b-c (contour). Note in Figures 6b-c that atoms in the same plane of the $\mathrm{Mg}$ (black circles) are pushed away, while those in the planes below and above (white circles) are drawn in closer to the $\mathrm{Mg}$ interstitial. The excess electron, which is located in the space between the $\mathrm{Mg}$ and its closest $\mathrm{Li}$, occupies mainly a $\mathrm{Mg}$ orbital of $p$-character (Figure 6a), which is quite understandable since the $\mathrm{Mg} 3 p$ orbitals are the lowest-lying unoccupied orbitals.

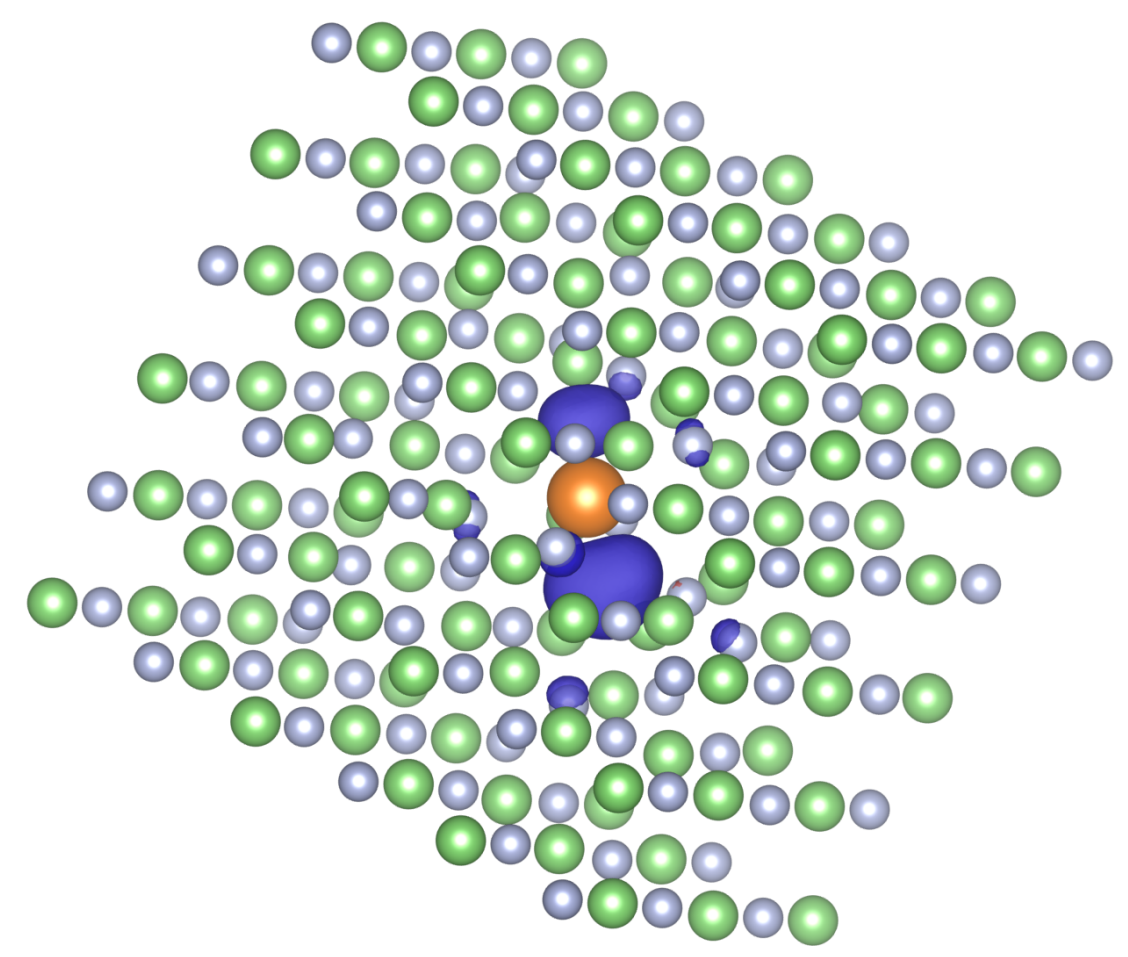

FIG.6a Spin density isosurface of the LiF:Mg+e-. The grey, green and orange symbols represent the F, Li and $\mathrm{Mg}$ atoms, respectively. The blue surface (value $0.0065 \mathrm{e} / \AA^{3}$ ) represents the spin density. 

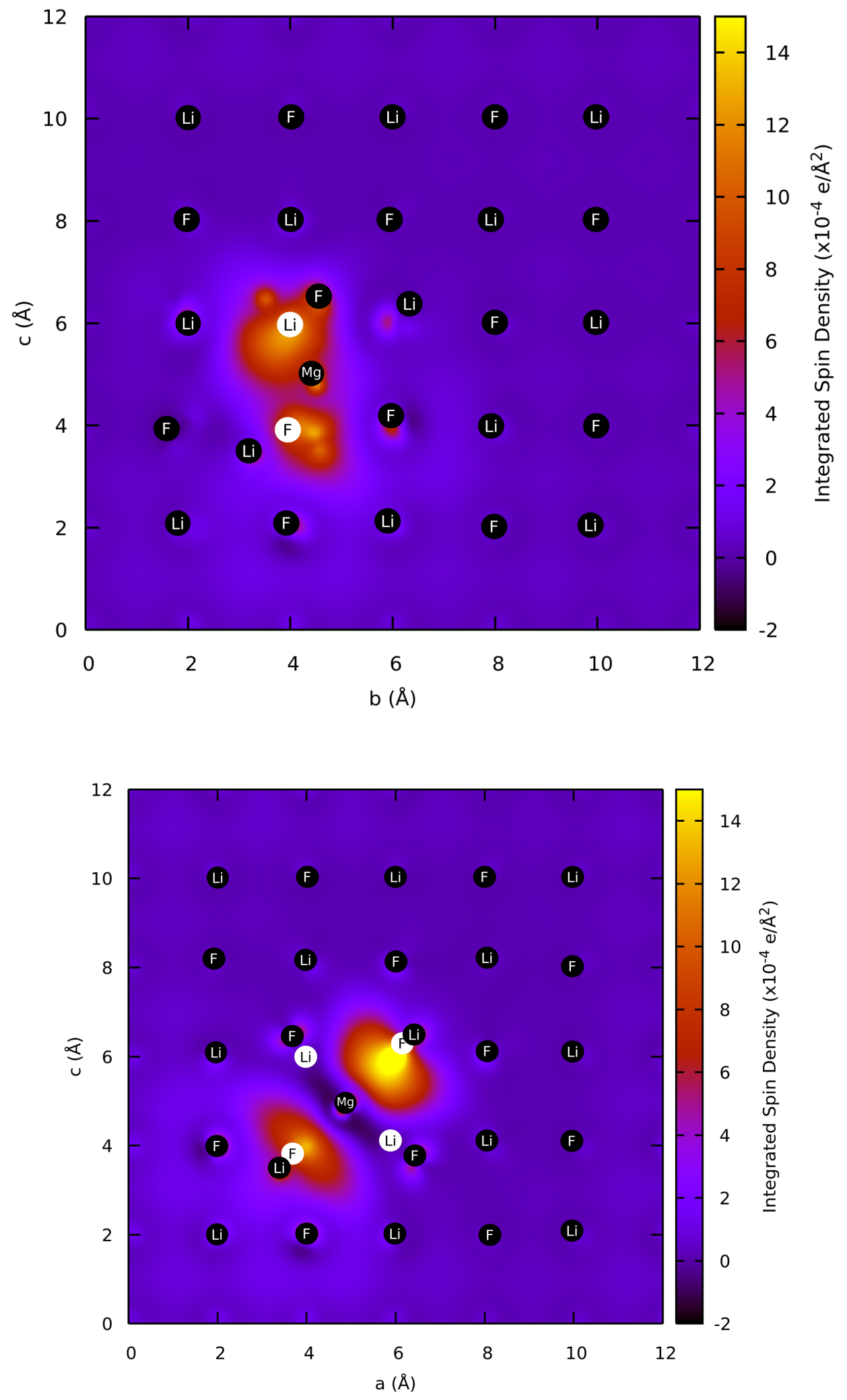

FIG.6b-c Two-dimensional contour plots of the LiF:Mg+e- spin density in planes containing the Mg-interstitial. Black circles indicate the location of the atoms in the plane of the contour, while white circles indicate atoms in the planes below and above. The largest contribution to the spin density is in the yellow region. 
Regarding LiF:Mg-Li $\mathrm{vac}_{\text {ac }}$ and $\mathrm{LiF}: \mathrm{Mg}-\mathrm{Li}_{\text {vac }}+\mathrm{e}^{-}$, no qualitative difference is observed between the hybrid functional and PBE, apart from a downward shift in energy levels. Both indicate an occupied and an empty state in $\mathrm{LiF}: \mathrm{Mg}-\mathrm{Li}_{\text {vac }}$ and only one occupied state in $\mathrm{LiF}: \mathrm{Mg}-\mathrm{Li} \mathrm{vac}_{\text {va }}+\mathrm{e}^{-}$as shown in Figure 3(h). Note in Figure 3(h) that in the presence of an excess electron, there is no defect level associated to the $\mathrm{Li}_{\text {vac }}$ and the only occupied state agrees very well with the $\mathrm{Mg}$ defect level (4.534 eV for LiF:Mg versus $4.544 \mathrm{eV}$ for $\mathrm{LiF}: \mathrm{Mg}-\mathrm{Li}_{\mathrm{vac}}+\mathrm{e}^{-}$). This implies that in the presence of radiation the two defect states $\mathrm{Mg}$ and $\mathrm{Mg}-\mathrm{Li}_{\mathrm{vac}}+\mathrm{e}^{-}$exhibit the same character and are very close in energy $(0.01 \mathrm{eV})$. It is, therefore, very difficult to distinguish between these two defects purely on the basis of spectroscopic data. Only a systematic analysis of the formation energy and the TTL, as will be done below, can clarify this matter.

The spin-density isosurface and contour plot for $\mathrm{LiF}: \mathrm{Mg}-\mathrm{Li}$ vac are shown in Figures $7 \mathrm{a}$ and $7 \mathrm{~b}$, respectively. Notice that for the neutral system, i.e. without excess electron, the $\mathrm{Mg}$ displaces a Li atom from its site by $\sim 0.76 \AA$ and takes its place in the lattice in substitutional position (Figure 7a), while the actual Li vacancy is nearby in the cell but not directly involved. The unpaired electron locates in an $s$-like orbital in the interstitial region adjacent to the $\mathrm{Mg}$ defect (Figure 7b).

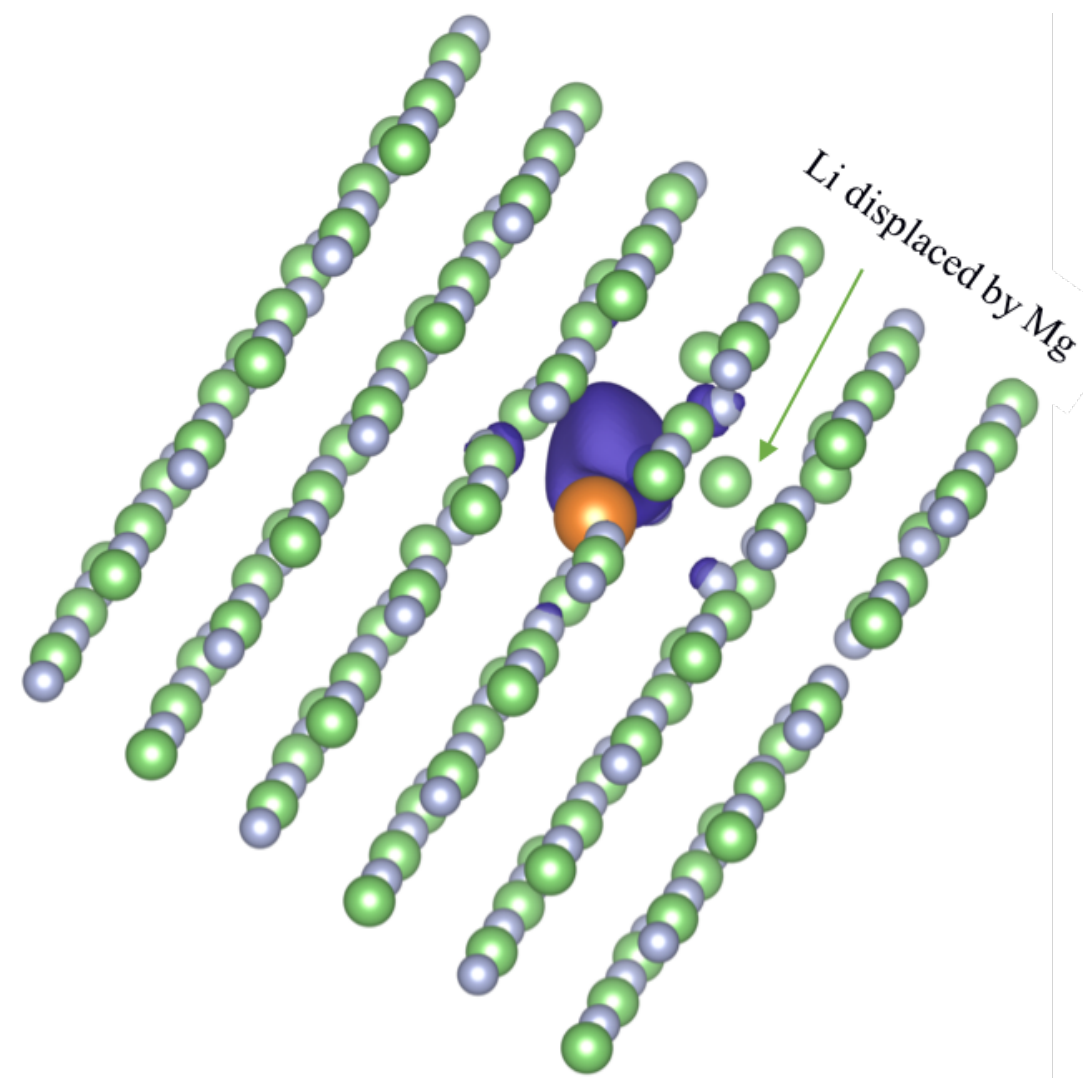

FIG.7a Spin density isosurface of the $\mathrm{LiF}: \mathrm{Mg}-\mathrm{Li}_{\text {vac. The }}$ grey, green and orange symbols represent the F, $\mathrm{Li}$ and $\mathrm{Mg}$ atoms, respectively. The blue surface (value $0.0065 \mathrm{e} / \AA^{3}$ ) represents the spin density. 


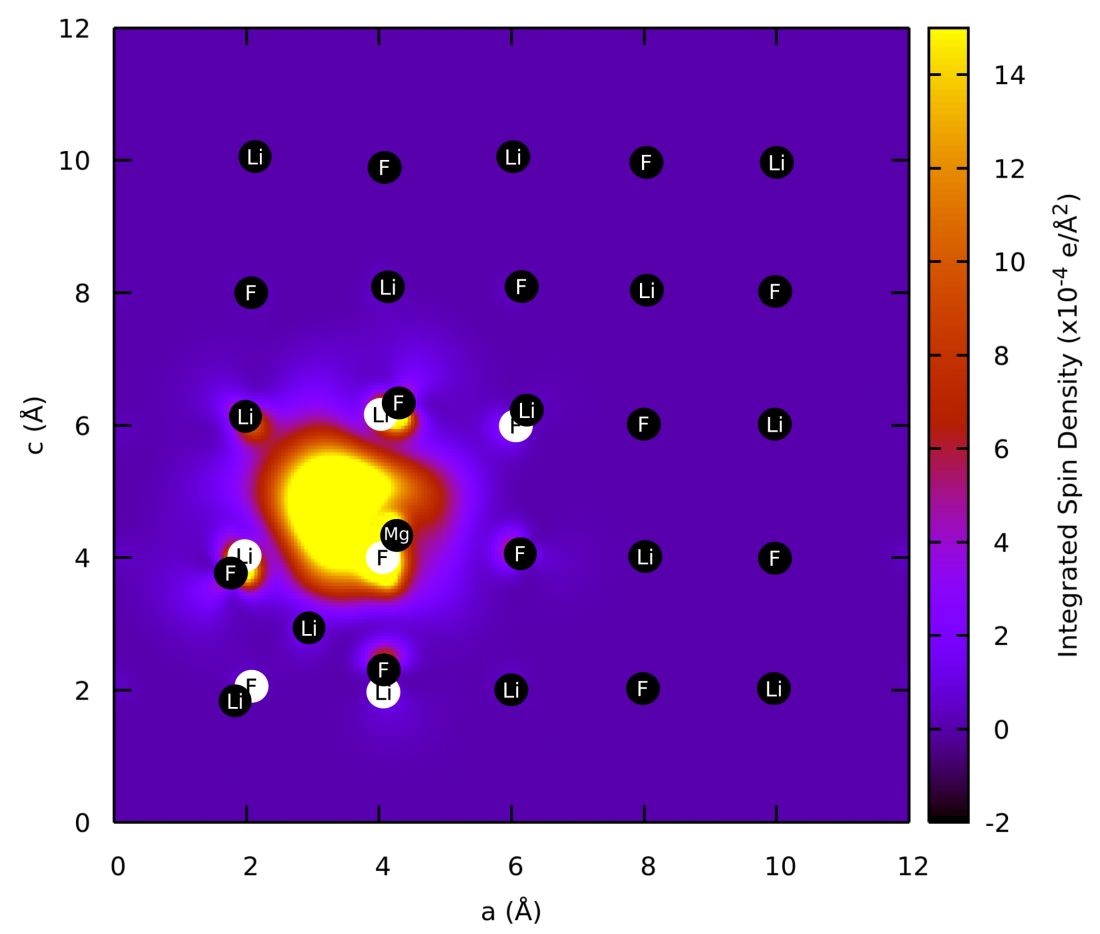

FIG.7b Two-dimensional contour plot of the LiF:Mg-Livac spin density in a plane containing the distortional space created by the Mg-interstitial. Colours are assigned as in Figure 6b-c.

In the presence of radiation, i.e. for $\mathrm{LiF}: \mathrm{Mg}-\mathrm{Li}_{\mathrm{vac}}+\mathrm{e}^{-}$, the $\mathrm{Li}$ atom that was relocated by the $\mathrm{Mg}$ returns close to its original position (only $0.25 \AA$ away) while the $\mathrm{Mg}$ returns to the interstitial tetrahedral position, creating a distortion similar to the LiF:Mg geometry. In this case, the displacement of the neighbouring Fluorine atoms is asymmetric; one moves by an averaged distance of $0.67 \AA$ while the other by $1.122 \AA$. The Li vacancy does not appear to have a direct involvement into the process. Based on this geometry analysis, the possibility of generating clusters of $\mathrm{Mg}-\mathrm{Li}_{\text {vac }}$ as proposed in a previous study [6] becomes questionable.

Similar to LiF:Mg-Li $\mathrm{i}_{\mathrm{vac}}$, no qualitative discrepancy is observed between PBE and PBE0 for all the defects with the $\mathrm{Mg}$ substitutional. Also note that for these defects, and in contrast to interstitial $\mathrm{Mg}$ defects, we do not observe a lattice distortion. The neutral $\mathrm{LiF}: \mathrm{Mg}-\mathrm{Li} \mathrm{i}_{\text {sub }}$ exhibits two defects levels located at $2.889 \mathrm{eV}$ and at $0.919 \mathrm{eV}$ below the CBM. The $2.889 \mathrm{eV}$ energy level could be associated to the unpaired electron of the $\mathrm{Mg} 3 \mathrm{~s}$ state as observed through the spin density shown in Figure 8. In the presence of radiation, only one defect state situated at $3.486 \mathrm{eV}$ is observed for $\mathrm{LiF}: \mathrm{Mg}-\mathrm{Li}_{\text {sub }}+\mathrm{e}^{-}$. Due to the fact that $\mathrm{Mg}^{2+}$ is a divalent ion, there is no net spin. Interestingly, this defect energy level is located very close to the $380 \mathrm{~nm}(3.263$ 
$\mathrm{eV}$ ) absorption band observed in the experiment [9-15] with a difference of $0.223 \mathrm{eV}$, similar to the $0.224 \mathrm{eV}$ discrepancy seen between the $\mathrm{LiF}: \mathrm{Mg}+\mathrm{e}^{-}$defect and the $310 \mathrm{~nm}(4 \mathrm{eV})$ experimental absorption band (see Table I). A geometry analysis reveals that for the LiF:Mg$\mathrm{Li}_{\text {sub}}$, the $\mathrm{Mg}$ substitutional causes the displacement of six nearest $\mathrm{F}$ atoms away symmetrically from their original site by a distance of $0.155 \AA$ and the closest Li atoms suffer negligible effect. While in the presence of an excess electron, the displacement of the six neighbouring $\mathrm{F}$ atoms is asymmetric where five of them move forward by $0.72 \AA, 0.4 \AA, 0.35 \AA, 0.25 \AA$ and $0.2 \AA$ whereas the other one moves back by $0.06 \AA$.

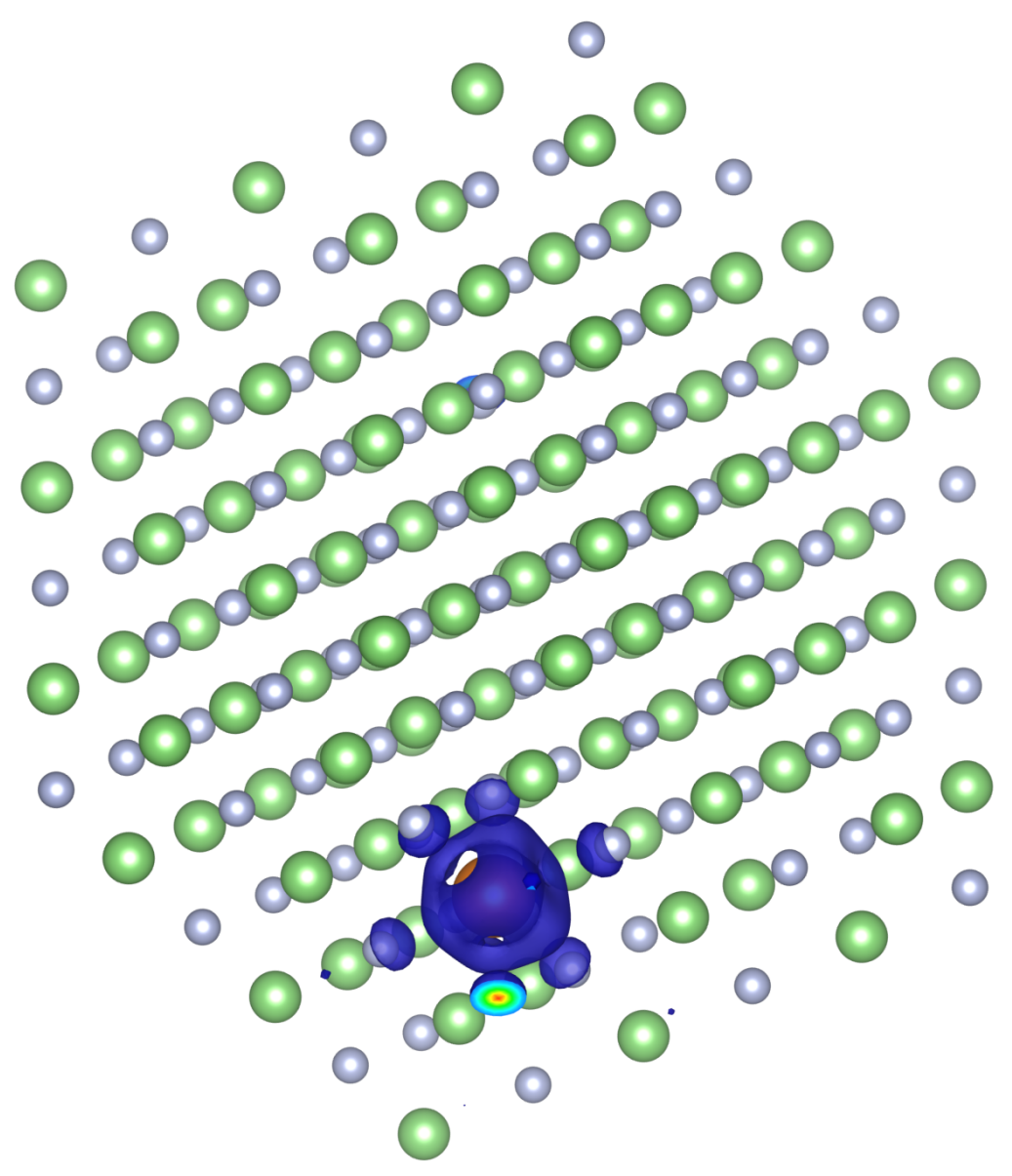

FIG.8 Spin density isosurface of the LiF:Mg-Lisub. The grey, green and orange symbols represent the F, Li and $\mathrm{Mg}$ atoms, respectively. The blue surface (value $0.005 \mathrm{e} / \AA^{3}$ ) represents the spin density

The energy levels obtained for the $\mathrm{LiF}: \mathrm{Mg}-\mathrm{Li}_{\mathrm{sub}}-\mathrm{Li}_{\mathrm{vac}}+\mathrm{e}^{-}$defect are quite similar to those for the $\mathrm{LiF}: \mathrm{Mg}-\mathrm{Li}_{\text {sub }}$ by a difference in energy less than $0.01 \mathrm{eV}$, regardless of the functional. This suggests that they share the same character. The spin density indicates that the excess electron 
is localised in the $\mathrm{Mg}-3 s$ state and the geometry analysis reveals that the $\mathrm{Mg}$ substitutional induces the displacement of six nearest $\mathrm{F}$ atoms symmetrically in pairs, by $0.14 \AA, 0.15 \AA$ and $0.18 \AA$, while one $\mathrm{F}$ atom close to the $\mathrm{Li}_{\text {vac }}$ by $0.15 \AA$. At the same time, three neighbouring $\mathrm{Li}$ atoms move away from their original position; two by $0.11 \AA$ and one by $0.14 \AA$.

\subsection{Formation energy and thermodynamic transition levels (TTL)}

From the data shown in Table II, we note that for a charge state $q=0$, i.e. for the neutral system, the $\mathrm{LiF}: \mathrm{Mg}-\mathrm{Li}_{\text {sub }}-\mathrm{Li}_{\text {vac }}$ defect is the most stable of the five defects considered here, with a formation energy of $2.53 \mathrm{eV}$. This is lower by $1.95 \mathrm{eV}, 4.76 \mathrm{eV}, 4.93 \mathrm{eV}$ and $7.80 \mathrm{eV}$ than the LiF:Mg-Li $\mathrm{L}_{\text {sub }}(4.48 \mathrm{eV}) \mathrm{LiF}-\mathrm{Mg}-\mathrm{Li}_{\text {vac }}(7.29 \mathrm{eV}), \mathrm{Mg}$ interstitial $(7.46 \mathrm{eV})$ and the F vacancy $(10.33 \mathrm{eV})$, respectively. For charge state $q=-1$ (i.e. for the charged systems), the difference in formation energy between $\mathrm{LiF}: \mathrm{Mg}+\mathrm{e}^{-}$and $\mathrm{LiF}: \mathrm{Mg}-\mathrm{Li}_{\mathrm{vac}}+\mathrm{e}^{-}$is $1.42 \mathrm{eV}$ in favour of the latter. Consequently $\mathrm{LiF}: \mathrm{Mg}-\mathrm{Li}_{\mathrm{vac}}+\mathrm{e}^{-}$has a higher probability to be created due to radiation exposure. Notice that this energy difference is actually independent of the value of $E_{F}$. Similarly, the $\mathrm{LiF}: \mathrm{Mg}-\mathrm{Li}_{\text {sub }}-\mathrm{Li}_{\text {vac }}+\mathrm{e}^{-}$defect has a formation energy 3.1 eV lower than $\mathrm{LiF}: \mathrm{Mg}-\mathrm{Li} \mathrm{vac}_{\text {vac }}+\mathrm{e}^{-}$, which means it has a higher probability to be created during the irradiation process than any other defects.

From the experimental standpoint [46], the neutral $\mathrm{LiF}: \mathrm{Mg}-\mathrm{Li}_{\mathrm{vac}}$ is stable when the energy level displayed in Figure 3(g) is located below the thermodynamic transition level (TTL) of $7.49 \mathrm{eV}$, while the charged $\mathrm{LiF}: \mathrm{Mg}-\mathrm{Li}_{\mathrm{vac}}+\mathrm{e}^{-}$defect is stable when the energy level displayed in Figure $3(\mathrm{~h})$ is situated above. The two defect energy levels shown in Table I for the neutral LiF:Mg$\mathrm{Li}_{\text {vac }}$ are situated at $7.588 \mathrm{eV}$ and $10.491 \mathrm{eV}$ above the VBM, which are both above the TTL by $0.1 \mathrm{eV}$ and $3 \mathrm{eV}$, respectively. This suggests that in the absence of radiation, the $\mathrm{LiF}: \mathrm{Mg}-\mathrm{Li} \mathrm{i}_{\mathrm{vac}}$ defects are not stable and do not appear to be feasible. In contrast, as shown in Figure 3(h), the defect energy level observed for $\mathrm{LiF}: \mathrm{Mg}-\mathrm{Li}_{\mathrm{vac}}+\mathrm{e}^{-}$is located $7.531 \mathrm{eV}$ above the VBM, i.e. above the TTL by $0.04 \mathrm{eV}$. Consequently, such a defect is thermodynamically stable, which means that the Li vacancy is more likely to be created during the irradiation process, as excess electrons are required to stabilize it. Comparing with data shown in Table I, the defect energy level for LiF:Mg is situated $7.541 \mathrm{eV}$ above the VBM and $0.779 \mathrm{eV}$ below the TTL, which implies that such a defect is stable in its neutral configuration and hence feasible under normal, nonirradiation conditions. In the presence of excess electrons, i.e. for $\mathrm{LiF}: \mathrm{Mg}+\mathrm{e}^{-}$, the two defect 
energy levels displayed in Table I are situated $7.851 \mathrm{eV}$ and $9.387 \mathrm{eV}$ above the VBM but 0.469 $\mathrm{eV}$ below and $1.067 \mathrm{eV}$ above the TTL, respectively. Consequently, one can argue that the $\mathrm{Mg}$ defect (blue squares in Figure 4) with an excess electron correspond to an energetically suitable charged state. The relatively large formation energy for the $\mathrm{Mg}$ defect close to the valence band maximum $(\sim 15.3 \mathrm{eV})$ suggests that the $\mathrm{Mg}$ interstitial cannot trap excess electrons in its empty states. Instead, as it is shown in Figures 6 and 7, it creates a local distortion, thus inducing an electronic state that is lower in energy than the $\mathrm{Mg}$ empty orbitals. First-principles (PBE) molecular dynamics simulations show that the excess electron is stable in this interstitial space.

For the neutral $\mathrm{LiF}: \mathrm{Mg}-\mathrm{Li}_{\text {sub }}$ we found two defect energy levels located at $9.47 \mathrm{eV}$ and 11.44 $\mathrm{eV}$ above the VBM which are above the TTL by $1.47 \mathrm{eV}$ and $3.44 \mathrm{eV}$. Consequently, these states are not stable for charge $q=0$. For the charged $\mathrm{LiF}: \mathrm{Mg}-\mathrm{Li}_{\text {sub }}+\mathrm{e}^{-}$, only one defect energy at $8.29 \mathrm{eV}$ above the VBM is observed, which is situated above TLL by $0.77 \mathrm{eV}$. This means that $\mathrm{LiF}: \mathrm{Mg}-\mathrm{Li}_{\text {sub }}+\mathrm{e}^{-}$is stable and energetically suitable. Concerning the neutral $\mathrm{LiF}: \mathrm{Mg}-\mathrm{Li} \mathrm{i}_{\text {sub }}-\mathrm{Li} \mathrm{i}_{\text {vac }}$, no defect levels are observed within the gap. Nevertheless, in the presence of radiation, i.e. of excess electrons, two defect energy levels at $9.20 \mathrm{eV}$ and $11.18 \mathrm{eV}$ appear above the VBM and are located above the TTL of $8.11 \mathrm{eV}$, by $1.09 \mathrm{eV}$ and $3.07 \mathrm{eV}$, respectively. This implies that $\mathrm{LiF}: \mathrm{Mg}-\mathrm{Li}_{\text {sub }}-\mathrm{Li}_{\text {vac }}+\mathrm{e}^{-}$is stable and energetically suitable.

In summary, the formation energy and thermodynamic transition level analysis performed in this work suggest that the $\mathrm{Mg}$ defect in its neutral and charged states as well as the LiF:Mg$\mathrm{Li}_{\text {vac }}, \mathrm{LiF}: \mathrm{Mg}-\mathrm{Li}_{\text {sub }}$ and $\mathrm{LiF}: \mathrm{Mg}-\mathrm{Li}_{\text {sub }}-\mathrm{Li}_{\text {vac }}$ defects in their charged state are acceptor levels, i.e. electron traps. Therefore, as stable defects, they will trap electrons generated by radiation= Irradiation can create $\mathrm{Li}$ and $\mathrm{F}$ vacancies while generating secondary electrons (and holes) by ionization. These secondary electrons can find a $\mathrm{Mg}$ trap and localise to form a charged $\mathrm{Mg}-\mathrm{e}^{-}$ defect, which is stable as it is located above the TTL. At the same time, irradiation can simultaneously: a) remove a $\mathrm{Li}$ atom nearby a $\mathrm{Mg}$ interstitial, creating a $\mathrm{Mg}$-Li $\mathrm{i}_{\text {vac }}$ defect; b) substitute a Li by a Mg atom inducing a $\mathrm{LiF}: \mathrm{Mg}-\mathrm{Li}_{\text {sub }}$ defect; and c) create a $\mathrm{Li}$ vacancy plus a $\mathrm{Mg}$ substitutional to form a $\mathrm{LiF}: \mathrm{Mg}-\mathrm{Li}_{\text {sub }}-\mathrm{Li}_{\text {vac }}$ defect, which will also capture a secondary electron above the TTL. The $\mathrm{LiF}: \mathrm{Mg}+\mathrm{e}^{-}$and $\mathrm{Mg}-\mathrm{Li}_{\mathrm{vac}}+\mathrm{e}^{-}$defects are very close in energy, both for interstitial and substitutional Mg.

We have also observed that the Li vacancy does not play a relevant role in the defect formation. Moreover, calculations of the $\mathrm{Mg}-\mathrm{Li}_{\mathrm{vac}}$ defect in a larger supercell containing 512 atoms with 
the Li vacancy located $6.5 \AA$ away from the Mg (compared to $4.9 \AA$ in the 216 -atom supercell), show that the spin density is practically unchanged (see supplemental material). This suggests that the location of the Li vacancy is probably immaterial to the structural and energetic characteristics of the charged defect; i.e. $\mathrm{Mg}$ and $\mathrm{Mg}-\mathrm{Li}_{\mathrm{vac}}$ charged defects are essentially the same. The results of this study shed new light into the role of $\mathrm{Mg}$ dopants in LiF dosimeters. In the absence of other traps, e.g. Ti dopants, irradiation will remove electrons from the (occupied) $\mathrm{Mg}-3 s$ orbitals leaving behind a hole, while the removed electrons will travel through the material until they find a suitable trap at a $\mathrm{LiF}: \mathrm{Mg}, \mathrm{LiF}: \mathrm{Mg}-\mathrm{Li} \mathrm{vac}_{\text {vac }}, \mathrm{LiF}: \mathrm{Mg}-\mathrm{Li}_{\text {sub }}$ or $\mathrm{LiF}: \mathrm{Mg}-$ $\mathrm{Li}_{\text {sub-Li }}-\mathrm{i}_{\text {vac }}$ defects. This interpretation is consistent with the suggestion of Mayhugh et al. [1314] who argued that the "TL-associated 310- $\mathrm{nm}(4.0 \mathrm{eV})$ absorption results from trapped electrons" in contrast to others experiments [10-12, 15].

\section{Conclusions}

The most common traps in $\mathrm{LiF}$ are $\mathrm{F}$ vacancies created mostly by the removal of $\mathrm{F}$-atoms due to irradiation [51]. The present results, however, suggest that interstitial Mg dopants can also trap electrons in locally distorted structures characterised by the displacement of neighbouring $\mathrm{Li}$ and $\mathrm{F}$ atoms. These charged defect states are thermodynamically stable. Consideration of these defects provides an interpretation for the observed 2.3-fold enhancement of the thermoluminescent response of $\mathrm{LiF}: \mathrm{Mg}$ compared to pure $\mathrm{LiF}$, when exposed to radiation [9], and for the increase in intensity of the $4 \mathrm{eV}$ band as the $\mathrm{Mg}$ dopant concentration increases [12]. That is, in addition to the regular F vacancies [51], the $\mathrm{Mg}$ defects, which can be considered as intrinsic defects introduced during the crystal growth procedure as well as the $\mathrm{LiF}: \mathrm{Mg}-\mathrm{Li} \mathrm{vac}_{\mathrm{va}}+\mathrm{e}$, $\mathrm{LiF}: \mathrm{Mg}-\mathrm{Li}_{\text {sub }}+\mathrm{e}^{-}$, and $\mathrm{LiF}: \mathrm{Mg}-\mathrm{Li}_{\text {sub }}-\mathrm{Li}_{\text {vac }}+\mathrm{e}^{-}$charged defects created during the irradiation process, result all in additional traps for electrons and hence in a higher TL intensity.

\section{Acknowledgments}

We are extremely grateful to the reviewers and the Editorial Board of J. Phys.: Cond. Mat. for the useful comments and insight provided during the revision process of the manuscript. The authors thank Declan Scullion, Malachy Montgomery from QUB, José Luis Gordillo Ruiz from C3-UNAM and Iain Bethune from Hartree Centre, Sci-Tech Daresbury for technical support. They also acknowledge Emilio Artacho, Lorenzo Stella, Myrta Grüning, Cedric Rocha Leão, Eric Shirley, and Kathleen Schwarz for useful discussions. GMJL was on sabbatical leave at 
Queen's University Belfast funded by DGAPA UNAM and Conacyt Mexico. This project is partially supported by Royal Society-Newton Advanced Fellowship grant NA150212 and PAPIIT-UNAM grant IN115117. We are grateful for computational support from the UK national high-performance computing (HPC) service, ARCHER, for which access was obtained via the UKCP consortium and funded by EPSRC grant ref EP/K013564/1 and from UNAM HPC service, Miztli, through grant ref. LANCAD-UNAM-DGTIC-334

\section{References}

[1] Massillon-JL G, Gamboa-deBuen I and Brandan M E 2006 J. Appl. Phys. 100103521

[2] Massillon-JL G, Gamboa-deBuen I and Brandan M E 2007 J. Phys. D: Appl. Phys. 40 2584

[3] Massillon-JL G, Cabrera-Santiago A, Minniti R, O’Brien M and Soares C 2014 Phys. Med. Biol. 594149

[4] Cabrera-Santiago A and Massillon-JL G 2016 Phys. Med. Biol. 617919

[5] McKeever S W S, Moscovitch M and Townsend P D 1995 Thermoluminescence Dosimetry Materials: Properties and Uses Nuclear Technology, Ashford, UK

[6] Horowitz Y S, Oster L, Biderman S, and Einav Y 2003 J. Phys. D: Appl. Phys 36446

[7] Zimmerman D W and Jones D E 1967 Appl. Phys. Lett. 1082

[8] Bilski P, Budzanowski M, Olko P, Waligorski M P R 1998 Radiat. Meas. 29355

[9] Klick C C, Claffy E W, Gorblcs S G, Attix F H, Schulman J H and Allard J G 1967 J. Appl. Phys. 383867

[10] J. Mort 1965 Solid St. Commun. 3263

[11] Crittenden C G, Townsend P D and Townshend S E 1974 J. Phys. D: Appl. Phys. 72397

[12] Seth P, Aggarwal S, Garg L, Bahl S, Lochab S P, Rao S M 2012 Nucl. Instrum. Methods B 27846

[13] Mayhugh M R, Christy R W and Johnson N M 1970 J. Appl. Phys. 412968

[14] Mayhugh M R 1970 J. Appl. Phys. 414776

[15] Nepomnyashchikh A I and Radzhabov E A1980 Opt. Spectrosc. 48154

[16] Bull R K, McKeever S W S, R Chen, Mathur V K, Rhodes J F and Brown M D 1985 J. Phys. D: Appl. Phys. 191321

[17] Karsai F, Tiwald P, Laskowski R, Tran F, Koller D, Gräfe S, Burgdörfer J, Wirtz L, and Blaha P 2014 Phys. Rev. B 89125429 
[18] Shluger A, Mysovsky S and Nepomnyashchikh 1988 J. Phys. Chem. Solids 491043

[19] Freysoldt C, Neugebauer J and Van de Walle C G 2009 Phys. Rev. Lett 102016402

[20] Van de Walle C G and Neugebauer J, 2004 J. Appl. Phys. 953851

[21] Goes W, Wimmer Y, El-Sayed A-M, Rzepa G, Jech M, Shluger A L, Grasser T 2018 Microelectronics Reliability $\mathbf{8 7} 286$

[22] Vandevondele J. et al. 2005 Comp. Phys. Commun. 167 103; CP2K version 3.0, the CP2K developers group (2015). See also Lippert G, Hutter J, and Parrinello M 1997 Mol. Phys. 92 477. CP2K is freely available from http://www.cp2k.org

[23] Borstnik U, VandeVondele J, Weber V, and Hutter J 2014 Parallel Computing 4047

[24] Hutter J, Iannuzzi M, Schiffmann F, and VandeVondele J 2014 Wiley Interdiscip. Rev. Comput. Mol. Sci., 4 15. CP2K: atomistic simulations of condensed matter systems. http://dx.doi.org/10.1002/wcms.1159

[25] Lippert G, Hutter J and Parrinello M 1997, Mol. Phys. 92477

[26] Goedecker S, Teter M and Hutter J 1996 Phys. Rev. B 541703

[27] Krack M 2005 Theor. Chem. Acc. 114145

[28] VandeVondele J and Hutter J 2007 J. Chem. Phys. 127114105

[29] Perdew J P, Burke K and Enrzerhof M 1996 Phys. Rev. Lett. 773865

[30] Petretto G and Bruneval F 2015 Phys. Rev. B 92224111

[31] Perdew J P, Ernzerhof M and Burke K 1996 J. Chem. Phys. 1059982

[32] Adamo C and Barone V 1999 J. Chem. Phys. 1106158

[33] Zhao Y and Truhlar D G 2008 Theor Chem Account 120, 215

[34] Marques M A L, Oliveira M J T and Burnus T 2012 Comp. Phys. Commun. 1832272

[35] Heyd J, Scuseria G E and Ernzerhof M 2006 J. Chem. Phys. 124219906

[36] Heyd J, Scuseria G E and Ernzerhof M 2003 J. Chem. Phys. 1188207

[37] Krukau A V, Vydrov O A, Izmailov A F and Scuseria G E 2006 J. Chem. Phys. 125 224106

[38] Guidon M, Hutter J, and VandeVondele J 2010 J. Chem. Theory Comput. 62348

[39] Guidon M, Hutter J, and VandeVondele J 2009 J. Chem. Theory Comput. 53010

[40] Grimme S, Antony J, Ehrlich S and Krieg H 2010 J. Chem. Phys. 132154104

[41] Ott H 1926 Zeitschrift fur Kristallographie 63222

[42] Merklin J F 1978 Nucl. Instrum. Methods 157519

[43] Koyama Y, Yamada Y, Tanaka I, Nishitani S R, Adachi H, Murayama M and Kanno R 2002 Materials Transactions $\mathbf{4 3} 1460$

[44] Piacentini M, Lynch G and Olson C 1976 Phys. Rev. B 135530 
[45] Wyckoff R W G, Crystal Structures, Interscience Second ed. (Publishers, New York, New York, 1963) 17-83

[46] Freysoldt C, Grabowski B, Hickel T, Neugebauer J, Kresse G, Janotti A and Van de Walle C G 2014 Rev. Mod. Phys. 86253

[47] Janak J F 1978 Phys. Rev. B 187165

[48] Di Valentin C, Palma G, and Pacchioni G 2011 J. Phys. Chem. C 115561

[49] Alkauskas A, Broqvist P and Pasquarello A 2011 Phys. Status Solidi B 248775

[50] Shluger A L, Heifers E N, Gale J D and Catlow C R A 1992 J. Phys.: Condens. Matter 4 5711

[51] Estermann I, Leivo W J and Stern O 1949 Phys. Rev. 75627 